\title{
PRÁTICAS INTERDISCIPLINARES NO ENFRENTAMENTO DA COVID-19 NA ESTRATÉGIA SAÚDE DA FAMÍLIA
}

Rosilande dos Santos Silva ${ }^{1}$

Patricia Nascimento ${ }^{1}$

Márcia Maria de Sousa ${ }^{1}$

Emanuelle Rocha da Purificação ${ }^{1}$

Mariana Pereira dos Santos 1

Rosilene Pereira Veras ${ }^{1}$

Carine de Jesus Soares ${ }^{2}$

Magno Conceição das Merces ${ }^{3}$

\author{
https://orcid.0000-0002-4525-9687 \\ https://orcid.org/0000-0002-3361-1954 \\ https://orcid.org/0000-0003-1706-7108 \\ https://orcid.org/0000-0001-7852-120X \\ https://orcid.org/0000-0002-9084-4498 \\ https://orcid.org/0000-0001-8604-7659 \\ https://orcid.org/0000-0001-7767-9443 \\ https://orcid.org/0000-0003-3493-8606
}

Objetivo: Descrever as experiências de residentes multiprofissionais na Estratégia Saúde da Família acerca da aplicação de ações interdisciplinares no enfrentamento do novo Coronavírus. Método: Estudo descritivo, do tipo relato de experiência realizado por residentes multiprofissionais do núcleo Saúde da Família em uma Estratégia Saúde da Família. O estudo foi desenvolvido em três fases: levantamento das problemáticas enfrentadas pela equipe; formulação do plano de contingência local com base a teoria da interdisciplinaridade e implementação das ações. Resultados: Evidenciou-se uma maior adesão da população as recomendações da equipe de saúde, observados na demarcação do fluxo de indivíduos que mostrou bons resultados, reduzindo o risco da transmissão viral entre pacientes e os profissionais da saúde, bem como possibilitou uma diminuição significativa da permanência dos usuários na unidade de modo que a população continuasse a ser assistida, garantindo a segurança de todos os atores envolvidos. Considerações finais: As práticas interdisciplinares têm se destacado nos mais diversos serviços de saúde como método de ascensão essencial para gestores, profissionais de saúde e estudantes na produção de relações mais atuantes de forma integrada no campo da saúde como um todo, principalmente no enfrentamento da pandemia.

Descritores: Educação em Saúde; Pandemias; Infecções por Coronavirus; Práticas Interdisciplinares.

\section{INTERDISCIPLINARY PRACTICES IN COPING WITH COVID-19 IN THE FAMILY HEALTH STRATEGY}

Objective: To describe the experiences of multiprofessional residents in the Family Health Strategy regarding the application of interdisciplinary actions for coping with the new Coronavirus. Method: This is an experience report by multiprofessional Family Health residents. The descriptive study was developed in three phases: the first, the survey of the problems faced by the team; the second stage was the formulation of a local contingency plan based on the theory of interdisciplinarity and the third was the implementation of these actions. Results: The population adherence to the recommendations from the health team was observed in the demarcation of the flow of individuals. Which showed good results, reducing the risk of viral transmission among patients and health professionals, as consequence of a significant decreased in permanence of users in the unit. Additionally, the population continues to be assisted, ensuring the safety of all actors involved. Conclusion: Interdisciplinary practices have stood out in the most diverse health services as an essential ascension method for managers, health professionals and students in the production of more active relationship in an integrated manner in the field of health as a whole, especially of coping with the pandemic. Descriptors: Health Education; Pandemics; Coronavirus Infections; Interdisciplinary practices.

\section{PRÁCTICAS INTERDISCIPLINARIAS AL ENFRENTAR COVID-19 EN LA ESTRATEGIA DE SALUD FAMILIAR}

Objetivo: Describir las experiencias del equipo de profesionales multidisciplinario en la Estrategia de Salud Familiar con respecto a la aplicación de acciones interdisciplinarias para enfrentar el nuevo Coronavirus. Método: Un estudio descriptivo, un informe de experiencia realizado por profesionales de la Unidad de Salud de la Familia. El estudio fue desarrollado en tres fases: la primera, la encuesta de los problemas que enfrenta el equipo; la segunda etapa fue la formulación del plan de contingencia local basado en la teoría de la interdisciplinariedad y la tercera fue la implementación de acciones. Resultados: Se observó una mayor adherencia de la población a las recomendaciones del equipo de salud, observada en la demarcación del flujo de individuos que mostró buenos resultados, reduciendo el riesgo de transmisión viral entre pacientes y profesionales de la salud, así como permitiendo una disminución significativa en permanencia de los usuarios en la unidad para que la población continúe siendo asistida, garantizando la seguridad de todos los actores involucrados. Conclusión: Las prácticas interdisciplinarias se han destacado en los servicios de salud más diversos como un método esencial para los gerentes, profesionales de la salud y estudiantes en la producción de relaciones más activas de manera integrada en el campo de la salud en general, y especialmente en este contexto para enfrentar la pandemia.

Descriptores: Educação em Saúde; Pandemias; Infecções por Coronavirus; Prácticas interdisciplinarias.

IUniversidade do Estado da Bahia (UNEB), Salvador, Bahia, Brasil.

${ }^{2}$ Universidade Estadual do Sudoeste da Bahia (UESB), Jequié, Bahia, Brasil.

${ }^{3}$ Universidade Federal da Bahia (UFBA), Salvador, Bahia, Brasil. 


\section{INTRODUÇÃO}

A pandemia do novo coronavírus, o SARS-Cov-2, se instalou recentemente, desencadeando casos da chamada COVID-19 em praticamente todos os países do mundo, inclusive no Brasil ${ }^{1}$, teve como origem a cidade de Wuhan na China. Segundo a Organização Pan-Americana da Saúde (OPAS) o surto da doença do novo coronavírus constitui uma emergência de saúde pública internacional marcada por 259.474 mortes até o início do mês de maio de $2020^{2}$

O advento dessa doença no Brasil trouxe grandes apreensões às autoridades, com isso, o Ministério da Saúde (MS), pautado em declarações da Organização Mundial de Saúde (OMS), vem estabelecendo medidas para a redução da infecção viral ${ }^{3}$ por meio do Sistema Único de Saúde (SUS), o qual tem sido essencial no delineamento ao combate à essa pandemia, tendo como uma das ferramentas os serviços de saúde ofertados por meio de muitos dispositivos, com ênfase a Estratégia Saúde da Família (ESF) ${ }^{4}$.

A abordagem da saúde pública na ESF, destaca-se pelo seu importante papel de atuação diretamente na comunidade, desenvolvendo ações de prevenção e promoção da saúde, de modo a atender os princípios de universalidade, integralidade e equidade, dispostos no SUS ${ }^{5}$. Assim, a ESF configura-se como porta de entrada preferencial do sistema de saúde, elemento fundamental na resposta global ao problema em questão, ofertando atendimento resolutivo e coordenando o cuidado em todos os níveis de atenção ${ }^{3}$. Entreposto a esse eixo, pode se citar também o Núcleo Ampliado de Saúde da Família (NASF), que tem como objetivo aumentar a resolutividade dos problemas populacionais, junto às equipes de saúde da famíliab.

A organização dos serviços na ESF orienta as práticas profissionais na lógica da promoção da saúde e prevenção de doenças, tornando-se uma proposta com dimensões técnica, política e regionalizada de acordo com os princípios do SUS e das necessidades da comunidade. Com isso, pressupõe-se que o processo de trabalho dos profissionais de saúde que desenvolvem suas práticas de cuidados nessas unidades proponha e execute ações pautadas na interprofissionalidade e nas práticas colaborativas, a fim de identificar e atender as demandas da população que habita na área de abrangência de suas unidades de saúde?

Dessa forma, as práticas interprofissionais são o caminho no enfrentamento de cenários calamitosos vivenciados hodiernamente. O desenvolvimento de educação em saúde, acolhimento e a mobilização, a participação da comunidade são potentes ferramentas para o fazer das equipes no cotidiano de vida, saúde e doença dos individuos $^{8-9}$

Para tanto, este cenário complexo impõe desafios às equipes multiprofissionais. Atentar para o comportamento desta pandemia nos respectivos territórios, configura-se importante para as ações desenvolvidas pela vigilância epidemiológica, portanto, torna imprescindivel a atualização de estratégias de enfrentamento, sobretudo, por meio de medidas que reduzam as desigualdades de acesso e iniquidades aos sistemas de saúde e a condições estruturais para o autocuidado ${ }^{10}$. Ressalta-se ainda, a importância da abordagem interprofissional na ESF, sobretudo, pelo aspecto de integridade nos cuidados de saúde ${ }^{11}$, pois no momento o saber de cada profissional compartilhado aponta-se como estratégia contra-hegemônica e torna-se crucial no combate ao Coronavírus.

Nesse contexto, a composição das Residências Multiprofissionais em Saúde (RMS) têm sido uma ferramenta para ações interprofissionais entre as equipes, além de apresentar um caráter de troca de conhecimentos e saberes com grandes potencialidades, o que contribui de modo significativo nas ações de enfrentamento da pandemia contra o coronavírus ${ }^{12}$.

Ademais, com vista a contribuir com o conhecimento técnico-científico, os profissionais residentes têm trabathado e direcionado em práticas colaborativas realizadas na ESF durante a Pandemia da COVID-19, com o propósito de discutir o agravo e fortalecer estratégias de prevenção. Assim, o presente estudo tem por objetivo descrever as experiências de residentes multiprofissionais na Estratégia Saúde da Família acerca da aplicação de ações interdisciplinares no enfrentamento do novo Coronavírus.

\section{MÉTODO}

\section{Tipo de estudo}

Trata-se de um relato de experiência, de caráter descritivo, que tem por finalidade relatar observações sistemáticas da realidade vivenciada durante as práticas de residentes de pós-graduação lato sensu, do tipo RMS vinculada a Universidade do Estado da Bahia (UNEB) em parceria com o Ministério da Saúde.

\section{Local do estudo}

As atividades do estudo foram desenvolvidas em uma Unidade de Saúde da Família (USF) no município de Salvador - Bahia.

\section{Período de realização da experiência}

A experiência iniciou-se no mês de março do ano de 2020 , período em que começaram as ações de reorganização dos serviços da Atenção Primária em Saúde no município. 


\section{Sujeitos envolvidos na experiência}

A experiência relatada foi vivenciada por oito residentes do primeiro ano do programa de RMS do Núcleo Saúde da Família durante a realização de práticas de enfretamento da COVID-19. O grupo foi composto por três enfermeiras, duas cirurgiãs-dentistas, uma fisioterapeuta, uma farmacêutica e uma nutricionista.

\section{Aspectos éticos}

Por se tratar de um relato de experienciais vivenciais, não houve necessidade de encaminhamento e aprovação por Comitê de Ética em Pesquisa (CEP). Salienta-se que foram resguardados a privacidade da instituição e as residentes envolvidas nesse estudo, conforme preconiza a Resolução 466/2012 do Conselho Nacional de Saúde.

\section{Objetivos da experiência}

O objetivo da experiência foi desenvolver práticas interdisciplinares no combate à COVID-19, informar as famílias quanto a origem, transmissibilidade e prevenção da doença, organizar a oferta dos serviços com vistas a integralidade do cuidado, minimizar o risco de contágio entre usuários dos serviços e profissionais de saúde.

\section{Descrição da experiência}

As práticas foram oportunizadas pela Residência Multiprofissional em Saúde da Família, a qual soma 40 horas de inserção no território - com ações técnicas, assistenciais e de extensão, com foco na formação voltada à prevenção, promoção e recuperação da saúde, por meio da educação permanente e participação popular.

As profissionais residentes assumiram o desenvolvimento técnico científico de acordo com sua área de atuação, porém levando em consideração os princípios da ação multiprofissional.

Nesse sentido, o estudo foi organizado didaticamente em três fases. A primeira consistiu na realização do diagnóstico situacional, levantamento das problemáticas enfrentadas pela equipe para discutir em profundidade a experiência da formação frente o cenário de Pandemia pela COVID-19, espaços voltados a estudos e discussões e reestruturação de todas as práticas realizadas no território. A segunda fase foi de sistematização de ideias, planejamento, impressões relacionadas ao fazer das residentes no enfrentamento da pandemia de COVID-19, e apresentação do plano de contingência local. Por fim, na terceira fase ocorreu a implementação das ações planejadas, utilizando-se de recursos como produzidos pela equipe multiprofissional.

A experiência foi marcada pelo desenvolvimento de ações interprofissionais, que teve como finalidade informar a comunidade sobre a COVID-19, por meio da edu- cação em saúde, quanto a origem, transmissibilidade e prevenção da doença, enfatizando a importância do isolamento social como estratégia de combate ao novo Coronavírus, além de contribuir com a reflexão dos profissionais de saúde a respeito das práticas multiprofissionais nos serviços e na gestão de problemas sanitários, principalmente no enfrentamento de desafios inéditos, a exemplo da atual pandemia. Foi possível ainda agregar conhecimento no campo científico referente às práticas multiprofissionais e interprofissionais associadas a educação em saúde, no contexto da APS, promovendo reflexões, inflexões questionamentos e aprimoramento do senso crítico dos profissionais de saúde.

\section{Atuação da equipe de Enfermagem}

O foco das ações de enfrentamento planejadas esteve voltado principalmente para a educação em saúde, as residentes de Enfermagem vivenciaram os atendimentos individuais agendados dos programas de pré-natal, acompanhamento do crescimento e desenvolvimento, atividades de escuta qualificada, roteiro de vacinas em pontos específicos dentro do território adscrito e domicílio, interconsultas, planejamento sistemático de ações, visitas domiciliares, cadastramento de familias junto aos agentes comunitários de saúde. Essas ações de territorialização oportunizou a identificação dos principais determinantes sociais em saúde que interferia no processo saúde doença cuidado daquela população diante de um cenário de pandemia.

Com intuito de viabilizar o modelo de Vigilância em Saúde, pautada numa atuação interprofissional e intersetorial, realizava-se o matriciamento dos casos, e juntamente ao NASF, utilizava serviços da assistência a cidadania promovido pelo grupo de apoio da UNEB, buscando intervir nos problemas de saúde instalados, em riscos e danos aqueles cidadãos que se encontravam em situação de vulnerabilidade social e infectado pela COVID-19.

As enfermeiras residentes também estiveram atuantes no telemonitoramento dos casos sintomáticos respiratórios. O acompanhamento via telefone era feito após consulta e avaliação dos pacientes suspeitos de Covid-19 na unidade de saúde da família. Os pacientes eram orientados a manter-se em isolamento domiciliar por um período de no mínimo 14 dias. O objetivo central da proposta foi evitar deslocamento e exposição desnecessária desses cidadãos para procurar o serviço de saúde, estratégia de combate a disseminação do Coronavírus. As equipes buscaram reforçar o acolhimento, ferramenta que vincula a relação entre equipe e usuários (as), proporcionando a humanização no cuidado e ampliando o acesso aos serviços, 
mesmo diante de uma distância geográfica.

Sendo assim, os pacientes recebiam os devidos cuidados e orientações em suas residências. Cabe ressaltar que, as práticas de telemonitoramento eram realizadas por qualquer profissional de nível superior inserido na equipe multiprofissional.

\section{Atuação da equipe de Odontologia}

No contexto da pandemia a rotina da odontologia da APS também foi modificada, seguindo as recomendações do MS, os atendimentos odontológicos eletivos foram suspensos com o objetivo de reduzir o número de infectados pela COVID-19, levando em consideração o elevado risco de contaminação cruzada durante os atendimentos

13. Desse modo, mantiveram-se apenas os atendimentos em caráter de urgências e emergências odontológicas, onde os pacientes que procurava por este atendimento, eram escutados, orientados e, quando necessária prescrita medicação.

Para além das ações de ambulatório, as residentes de Odontologia estiveram atuantes em atividades generalistas e sanitárias, compondo as equipes de acolhimento, responsáveis por organização do fluxo de chegada na unidade e encaminhamento de casos suspeitos para triagem com equipe responsável, além da realização de salas de espera e desenvolvimento de material audiovisual disponibilizado em redes sociais.

Diante do grande desafio de combater a pandemia COVID-19, uma das estratégias incorporadas na USF foi a sinalização no piso e em cadeiras, com distanciamento mínimo de um metro e oitenta centímetro entre as pessoas que ali esperavam atendimento, objetivando atender a normativa do munícipio.

Ademais, junto às equipes da ESF e NASF, buscou-se contemplar ao máximo as ações de promoção de saúde, com abordagens coletivas para toda comunidade, porém com atenção especial aos grupos mais vulneráveis, considerados de risco elevado para o adoecimento e suspeitos da COVID-19 na comunidade.

\section{Atuação da equipe NASF}

As principais atividades do NASF, como atividades em grupo, o Programa Saúde na Escola (PSE) e atividades de educação em saúde na comunidade, foram suspensas e/ ou modificadas durante o período de enfrentamento da pandemia da COVID-19, a partir disso, houve um reordenamento das atividades, a fim de continuar a realizar ações de prevenção, promoção e proteção à saúde, por meio de estratégias voltadas principalmente à educação em saúde. Foram elas, criação de cartilha de orientações para usuários encaminhados para isolamento domici- liar; criação de série de áudios informativos em formato de podcast com orientações de hábitos de vida saudáveis (alimentação e atividade física); cuidados referentes ao risco de contaminação por COVID-19; orientação aos usuários (as) em polifarmácia; protocolo de dispensação de medicamentos e fortalecimento de redes e vínculos em grupos de redes sociais com a comunidade.

Através da intersetorialidade, realizou-se encaminhamentos para o abrigo social, doação de alimentos e produtos de limpeza. As residentes articuladas a órgãos públicos buscaram sanar problemas complexos, como isolamento domiciliar em moradias impróprias e desenvolveu ações voltada para aqueles indivíduos vulneráveis, procurando atuar nessa perspectiva, ampliando a abordagem intersetorial. Além disso, realizou-se visitas à feira livre e estabelecimentos comerciais a fim de propagar medidas preventivas de saúde.

\section{Principais resultados alcançados}

Diante da necessidade de adequação, às ações de educação em saúde implementadas foram repensadas, de modo que a população continuasse a ser assistida dentro de suas necessidades, sendo condizente com as perspectivas da promoção da saúde, uma vez que essas ações devem se apresentar enquanto instrumento capaz de estimular o empoderamento dos indivíduos e da coletividade não obstante disso, garantir a segurança dos usuários (as) e profissionais.

Constatou-se que, o fluxo de atendimento e demanda espontânea sofreu mudança, houve uma diminuição significativa da permanência dos usuários (as) na unidade, algumas demandas passaram a vir articuladas ao trabalho prestado pelos agentes comunitários de saúde, viabilizando otimização da lógica programada. Portanto, a experiência com a demarcação do fluxo de pessoas tem dado bons resultados, reduzindo o risco da transmissão viral entre pacientes e os profissionais da saúde.

As consultas de cuidados continuado foram gerenciadas conforme às especificidades dos usuários (as) de saúde, de modo que a população continuasse a ser assistida, garantindo a segurança dos usuários (as) e profissionais.

A atuação da Equipe de Saúde Bucal (ESB) na ESF representa o trabalho em equipe interdisciplinar e a integralidade do cuidado por meio de ações que valorizam o vínculo com a comunidade através ações continuadas ${ }^{14}$ A integração do cirurgião dentista e das residentes de Odontologia junto a equipe representa a ruptura do isolamento profissional para a produção de relações mais atuantes de forma integrada no campo da saúde como um todo, principalmente no enfrentamento da pandemia. 
Ao perceberem a velocidade de transmissibilidade da doença, as atitudes das pessoas consideradas grupo de risco foram repensadas, aqueles que já tinha outras patologias, adotam comportamentos que o torne menos suscetíveis a contaminação pela COVID-19 e/ou situações que agravam a doença instalada.

As gestantes e puérperas acompanhadas, mostraram-se prontificadas a adesão às orientações ressaltadas pela equipe durante as consultas de pré-natal e puerpério compreendendo a magnitude da Pandemia no período gravídico e a importância de um acompanhamento responsável.

De forma geral, as ações educacionais que buscavam informar a comunidade sobre as formas de contágio e proteção contra o Coronavírus, esclareceram dúvidas, muitas destas relacionadas a Fake News, alertaram a população quanto a necessidade e motivação para a prática do distanciamento social, o que consequentemente diminui a movimentação dentro e no entorno da unidade e sensibilizaram sobre a importância da utilização das máscaras artesanais, o que ocasionou maior adesão.

\section{LIMITAÇÕES DA EXPERIÊNCIA}

Expõe-se como limitações desse estudo sua abrangência restrita, os resultados apresentados referem a uma única instituição de saúde naquele município. Não podendo, assim, ser posto como mecanismos de práticas, pois cada território/equipe apresenta particularidades específicas.

Outro obstáculo em questão foi a duração das práticas, o curto espaço de tempo limita a melhor expressão do resultado, visto que o episódio de pandemia no território brasileiro não se findou e não sabemos quando acabará, logo, o comportamento dos indivíduos podem sofrer influência a diversos fatores disparados pela pandemia.

A ausência de estudos que possam corroborar para desenvolvimento de práticas promissoras do cuidado no enfrentamento da COVID-19, assim como o extenso território adscrito, são fatores que interfere negativamente na disseminação de práticas.

\section{Contribuições Ppra a Prática}

A integração dos residentes com as estratégias de atenção primária voltadas às práticas interdisciplinares favorece sua qualificação e entendimento sobre a ação dos profissionais de saúde da família dentro de seu território de atuação. Desse modo, as ações de residentes durante período de pandemia tem sido importante instrumento para o desenvolvimento de atividades interdiscipli- nares mesmo em situações atípicas e inéditas, e alguns dos produtos gerados durante o processo de enfrentamento podem ser implementadas de modo mais efetivo.

As ferramentas metodológicas do processo de educação em saúde, favorece e fortalece a atuação da equipe multiprofissional com a comunidade, facilita o processo de construção de vínculo entre os profissionais envolvidos e a população. Amplia a dimensão profissional, para além de métodos assistenciais e consultórios, possibilitando ao profissional de saúde, aprimorar estratégias, desenvolver a criatividade de modo a favorecer o interesse e a participação popular ${ }^{15}$, contribui ainda na remodelação profissional, através do desenvolvimento de novas habilidades e competências para lidar com a diversidade cultural, histórica, social, religiosa, ou seja, as particularidades de cada grupo social.

\section{CONSIDERAÇÕES FINAIS}

Conclui-se que as práticas interdisciplinares são fundamentais e vêm ganhando espaço nos mais diversos serviços de saúde. Com o intuito de que seja reconhecida como método de ascensão a saúde torna-se fundamental que gestores, profissionais de saúde, estudantes, estejam mais articulados nos serviços e compreendam sua real importância.

Intervenções como essas são essenciais nem só em tempo de pandemias, visto que a educação em saúde exerce papel primordial na APS, proporcionando práticas reflexivas, integrando ensino-serviço transformando assim o desempenho profissional e a qualidade dos serviços de saúde. Portanto, o SUS precisa expandir no sentido dessas atividades, empenhando cada vez mais de modo que essas praxes tomem dimensões em todos os níveis de atenção.

Espera-se que este relato de experiência, através dos apontamentos dos desafios encontrados, bem como sobre a potencialidade e desfecho das oportunidades e ensinamentos proporcionados, contribua para o desenvolvimento de comportamento favorável ao cuidado em saúde, permitindo o empoderamento pelo alcance de estratégias que permitam melhorias sobre as condições de vida, individual e coletiva.

Contribuições dos Autores: RSS; MMS: concepção e/ ou desenho do estudo. RSS; PNR; MMS; ERP; RPV e MPS: coleta, análise e interpretação dos dados. RSS; MMS e CJS: redação e/ou revisão crítica do manuscrito. CJS e MCM: aprovação da versão final a ser publicada. 


\section{REFERÊNCIAS}

1. Tuñas ITC, Silva ET, Santiago SBS, Maia KD, Silva-Júnior GO. Doença pelo Coronavirus 2019 (COVID-19): Uma abordagem preventiva para Odontologia. Rev. Bras. Odontol [Internet]. 2020 [acesso em 09 maio 2020];77:el766. Disponivel em: DOI: http://dx.doi.org/10.18363/ rbo. v77.2020.el766.

2. Organização Pan-Americana da Saúde (OPAS). Folha informativa - COVID-19 (doença causada pelo novo coronavírus). Brasilia - DF: OPAS; 2020 [citado em 08 de maio de 2020]. Disponivel em: https:// www.paho.org/bra/index.php?option=com_ content\&view=article\&id=6101:COVID198Itemid $=875$

3. Ministério da Saúde (BR). Secretaria de Atenção Primária à Saúde (SAPS). Protocolo de manejo clínico do coronavirus (COVID-19) na Atenção Primária à Saúde. Brasilia: Ministério da Saúde; abril de 2020. 7ạ versão. [Internet]. 2020 [cited 2020 abr 26]; Available from: https://www.unasus.gov.br/especial/COVID19/pdf/37

4. Mattos JCO, Balsanelli AP. A liderança do enfermeiro na atenção primária à saúde: revisão integrativa. Enferm Foco [Internet]. 2019 [cited 2020 Abr 27]; 10(4): 164-171. Available from: http://revista.cofen.gov.br/index.php/enfermagem/article/ view/2618/621.

5.Macinko J, Mendonca, CS. Estratégia Saúde da Familia, um forte modelo de Atenção Primária à Saúde que traz resultados. Saúde debate [Internet]. 2018 [cited 2020 May 09] : 42(spel): 18-37.Available from: http://www.scielo.br/scielo.php?script=sci_ arttext\&pid=S010311042018000500018\&lng=pt. https://doi.org/10.1590/0103-11042018s102.

6.Tesser CD. Núcleos de Apoio à Saúde da Familia, seus potenciais e entraves: uma interpretação a partir da atenção primária à saúde. Interface (Botucatu) [Internet]. 2017 Sep [cited 2020 May 09]; 21(62): 565-578. Available from: http://www.scielo.br/scielo.php?script=sci_ arttext\&pid=S1414-32832017000300565\&lng=en. Epub Nov 03, 2016. https://doi.org/10.1590/1807-57622015.0939.

7. Reis JG, Harzheim E, Nachif MCA, Freitas JC, D’Ávila O, Hauser L, et al. Criação da Secretaria de Atenção Primária à Saúde e suas implicações para o SUS. Ciênc. Saúde colet. [Internet]. 2019 Sep [cited 2020 May 10]; 24( 9 ): 3457-3462. Available from: http://www. scielo.br/scielo.php?script=sci_arttext\&pid=S141381232019000903457\&lng=en. Epub Sep 09, 2019. https://doi.org/10.1590/141381232018249.18612019

8.Guimarães RM, Meira KC, Paz EPA, Dutra VGP, Campos CEA. Os desafios para a formulação, implantação e implementação da Política Nacional de Vigilância em Saúde. Ciênc. Saúde colet. [Internet]. 2017 May [cited 2020 abr 21]; 22( 5 ): 1407-1416. Available from: http://www.scielo.br/scielo.php?script=sci_arttext\&pid=S1413-81232017002501407\&lng=en. http://dx.doi.org/10.1590/141381232017225.33202016.

9. Mallmann DG, Galindo NNM, Sousa JC, Vasconcelos EMR. Educação em saúde como principal alternativa para promover a saúde do idoso. Ciênc. saúde col. [Internet]. 2015[citado 09 de maio 2020]; 20(6): 1763-1772. Disponivel em: http://www.scielo.br/scielo. php?script=sci_arttextEpid=S141381232015000601763\&lng=en. https://doi.org/10.1590/1413-81232015206.02382014.

10. Rafael RMR, Neto M, Carvalho MMB, David HMSL, Acioli S, Faria MGA. Epidemiology, public policies and Covid-19 pandemics in Brazil: what can we expect?Rev. Enferm. UERJ, 2020 [cited 2020 May 09]: 28: e49570. Available from: https://www.e-publicacoes.uerj.br/index. php/enfermagemuerj/article/view/49570/33134 doi:https://doi.org/10.12957/reuerj.2020.49570.

11. Silva MVS, Miranda GBN, Andrade MA. Sentidos atribuidos à integralidade: entre o que é preconizado e vivido na equipe multidisciplinar Interface (Botucatu) [Internet]. 2017 [cited 2020 may 09]; 21(62): 589-599. Availablefrom:http://www.scielo.br/scielo.php?script=sci_ arttext8pid=S1414328320170003005898lng=en. Epub Feb 13, 2017. https://doi.org/10.1590/1807-57622016.0420.

12. Martins GDM, Caregnato RCA, Barroso VLM, Ribas DCP. Implementation of multi-professional healthcare residency at a federal university: historical trajectory. Rev. Gaúcha Enferm. [Internet]. 2016 [cited 2020 may 09] ; 37( 3 ): e57046. Available from: http://www. scielo.br/scielo.php?script=sci_arttextEpid=S1983-144720160003004058lng=en. Epub Aug 25, 2016. https://doi.org/10.1590/19831447.2016.03.57046.

13. Ministério da Saúde (BR). Atendimento Odontológico no SUS. Brasília, DF: Secretaria de Atenção Primária à Saúde (SAPS); [Internet]. 2020 Mar. [citado 18 de abril 2020] Disponivel em:http://croal.org.br/v4/arquivos/COVID-19_ATENDIMENTO_ODONTOLOGICO_NO_ SUS.pdf

14. Santos NML, Hugo FN. Formação em Saúde da Familia e sua associação com processos de trabalho das Equipes de Saúde Bucal da Atenção Básica. Ciênc. Saúde colet. [Internet]. 2018 [cited 2020 may 09]; 23(12): 4319-4329. Available from: http://www.scielo.br/scielo. php?script=sci_arttext\&pid=S1413-81232018001204319\&lng=en. https://doi.org/10.1590/1413-812320182312.12922016.

15. Moll MF, Boff NN, Silva PS, Siqueira TV, Ventura CAA. O enfermeiro na saúde da familia e a promoção de saúde e prevenção de doenças. Enferm. Foco. 2019. [citado 09 de maio 2020]; 10 (3).134-140. Disponivel em: http://revista.cofen.gov.br/index.php/enfermagem/ article/view/2001 